\title{
The Novel Patient with BLNK Gene Type of Agammaglobulinemia
}

\section{Gulnara Mahammadali Nasrullayevaㅁ, Vafa Rustam Mammadova', Afaq Vladimr Khalilova1, Shabnam Eldar Shahgeldiyeva²}

\author{
${ }^{1}$ Azerbaijan Medical University, Immunology Department, Baku, Azerbaijan \\ ${ }^{2}$ Khazar University, Baku, Azerbaijan \\ Email: eshahgaldiyev@khazar.org
}

How to cite this paper: Nasrullayeva, G.M., Mammadova, V.R., Khalilova, A.V. and Shahgeldiyeva, S.E. (2017) The Novel Patient with BLNK Gene Type of Agammaglobulinemia. Open Access Library Journal, 4: e4114.

https://doi.org/10.4236/oalib.1104114

Received: November 3, 2017

Accepted: November 25, 2017

Published: November 28, 2017

Copyright $\odot 2017$ by authors and Open Access Library Inc.

This work is licensed under the Creative Commons Attribution International License (CC BY 4.0).

http://creativecommons.org/licenses/by/4.0/

\begin{abstract}
Background: Agammaglobulinemia (AGM) is a genetic immune system disorder in which the body could not produce antibodies. There are two types of this disease: X-linked AGM (XLA) and autosomal forms. X-linked agammaglobulinemia results from a mutation in the gene for Bruton's tyrosine kinase (BTK), found on the X chromosome. Mutations in BTK result in lack of mature B-cells and immunoglobulins of all classes. There are 8 types of autosomal forms which are reflected in different defective genes. 7-year-old male patient at the age of $1-6$, was encountered the recurrent broncho-pulmonary and gastro-intestinal infections, furunculosis and recurrent otitis. Also, because of the strain, pain and swelling on the $4^{\text {th }}$ finger of the right hand it was suspected that the patient had rheumatoid arthritis. On immunological investigation, we have found out of absent of B lymphocyte. Level of IgG was 10 times less; IgA, IgM and IgE levels were 3 to 8 times less than the norm. Quantity of T-lymphocytes: absolute number of CD4+ lymphocytes increased, CD3+ and CD8+ lymphocytes were also high. Phagocyte activity in NBT, absolute number of NK cells and IRI index were 2 times lower than the norm. Genetically analysis has discovered the presence of abnormal homozygous BLNK gene.
\end{abstract}

\author{
Subject Areas \\ Immunology \\ Keywords \\ BLNK Gene, Rheumatoid Arthritis, Agammaglobulinemia
}

\section{Introduction}

Agammaglobulinemia is a disorder which passed through families when a per- 
son has very low levels of protective immune system proteins-immunoglobulins (Ig). Low levels of these antibodies make you more likely to get infected [1] [2] [3]. Mother carrying the defective gene passes this anomaly to the fetus; moreover, the clinical signs of disease are usually observed in boys. There are two types of this disease (Figure 1).

$\mathrm{X}$-linked agammaglobulinemia results from a mutation in the gene for Bruton's tyrosine kinase (BTK), found on the X chromosome. BTK is a nonreceptor cytoplasmic tyrosine kinase involved in B-cell receptor intracellular signaling, developing and differentiating [4] [5]. Loss-of-function mutations in BTK result in lack of mature B-cells and immunoglobulins of all classes. $50 \%$ of the mutations are new and these patients do not have a family history of the current condition. The other type with low or absent serum immunoglobulins is early onset non-Bruton agammaglobulinemia. Agammaglobulinemias with autosomal recessive/dominant heritage represent a very heterogeneous group, such as common immunoglobulin deficiency with increased only immunoglobulin $M$ (hyper-IgM syndrome), which is also discussed separately. Approximately $90 \%$ of patients with early-onset agammaglobulinemia and absence of B cells have abnormalities in the Btk gene [3] [6] [7].

Similar phenotype to that of the X-linked form, autosomal inheritance of agammaglobulinemia, has been detected in a small number of families and accounts for up to $15 \%$ of patients with agammaglobulinemia. Males and females are usually affected in equal order. More than 100 cases of autosomal agammaglobulinemia have then been informed to date. Their diagnosis was suspected on the basis of early susceptibility to severe recurrent or persistent infections [8]. The case is particularly true if the parents are consanguineous or the ones belonging to an isolated population. Abnormal laboratory parameters include low Ig levels and low or absent peripheral blood mature B lymphocytes [5] [9]. For determine the genetic defect and to confirm the diagnosis, should be performed molecular genetic testing. Table 1 shows the existing 8 types of agammaglobulinemia (AGM) which are reflected in defective genes.

We have patient withAGM4 type of disease which caused by homozygous mutation in the BLNK gene on chromosome 10q23.2. In these case B-cell development fails because of mutations B-cell linker protein [2] [8].

The BLNK gene encodes a B-cell linker protein. Linker or adaptor proteins can provide mechanisms by which receptors can increase and regulate to downstream effectors proteins. BLNK has essential role for normal B-cell development. BLNK is exclusively expressed in hematopoietic cells, mainly in progeny-

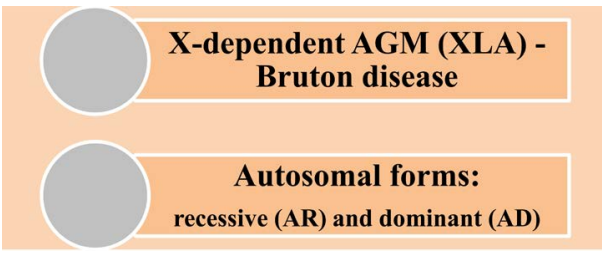

Figure 1. Two types of agammaglobulinemias. 
Table 1. Types and defective genes of autosomal agammaglobulinemias.

\begin{tabular}{cccc}
\hline Disease & Gene/Locus & Location & Inheritance \\
\hline AGM1 & IGHM & $14 \mathrm{q}$ & $\mathrm{AR}$ \\
AGM2 & IGLL1 & $22 \mathrm{q} 11$ & $\mathrm{AR}$ \\
AGM3 & CD79A & $19 \mathrm{q} 13.2$ & $\mathrm{AR}$ \\
AGM4 & BLNK & $10 \mathrm{q} 23.2$ & $\mathrm{AR}$ \\
AGM5 & LRRC8 & $9 \mathrm{q} 34.11$ & $\mathrm{AD}$ \\
AGM6 & CD79B & $17 \mathrm{q} 23.3$ & $\mathrm{AR}$ \\
AGM7 & PIK3R1 & $5 \mathrm{q} 13.1$ & $\mathrm{AR}$ \\
AGM8 & TCF3 & $19 \mathrm{p} 13.3$ & $\mathrm{AD}$ \\
\hline
\end{tabular}

AGM: agammaglobulinemia; AR: autosomal recessive; AD: autosomal dominant

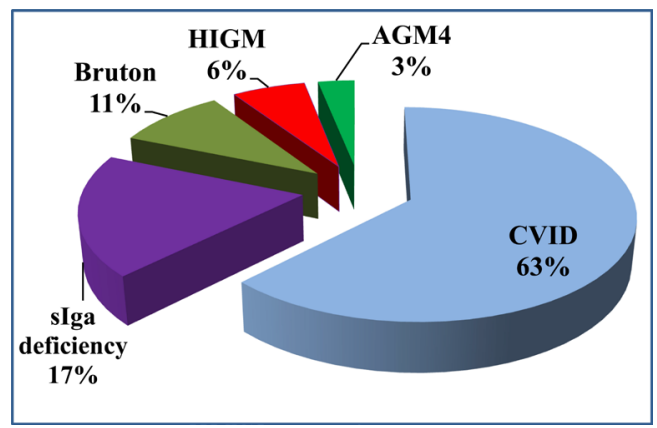

Figure 2. Different types of antibody deficiencies.

tor if myeloid cells, also in B cells [2] [9].

Clinical features on autosomal recessive agammaglobulinemia and X-linked agammaglobulinemia are similarly identical. When maternal transplacentally passed antibodies disappear patients develop recurrent pyogenic infections from 6 months of age. Sinopulmonary infections (especially sinusitis, pneumonia), otitis media are most commonly, followed by skin infections, gastrointestinal infections, sepsis, meningitis and osteomyelitis [3] [8] [10] [11] [12].

\section{Patients and Materials}

During 2010-2017 years Immunology Department and Pediatric Department of Azerbaijan Medical University have detected 35 patients with Antibody deficiencies, out of which 22 patients with CVID, 6 patients with sIgA deficiency, 4 patients with Bruton disease, 1 patient with AGM4 and 2 patient with HIGM. This investigation had been done in frame of collaboration with biological laboratory of Khazar University research group. Different types of antibody deficiencies are depicted in Figure 2.

\section{Case Report}

7-year-old male patient was born with normal height and weight from the first pregnancy. Parents were close relatives (cousins). Physical and mental develop- 
ment of the patient proceeded normally until 1 year. Nevertheless, later, at the age of $1-6$, he started to face the recurrent broncho-pulmonary and gastro-intestinal infections, furunculosis and recurrent otitis. At the age of 6 patient had pneumonia with high fever and respiratory symptoms. Also, because of the strain, pain and swelling on the $4^{\text {th }}$ finger of the right hand it was suspected that the patient had rheumatoid arthritis (Figure 3).

\section{Discussion}

Interestingly, there was not observed any pathological change in the mile-wrist joint in radiography. ASO, RF indexes were negative and CRP was high (110 $\mathrm{mg} / \mathrm{l}$ ). We have detected hepatosplenomegaly on US investigation (hepatomegaly: left part-57mm, splenomegaly: $96 \mathrm{~mm}$ ). ANA, specific M. tuberculosis and brucellosis antibodies were also negative. On X-Ray investigation it was detected pneumonia of left the part of lung and hidrotoraks.

\subsection{Immunology}

On immunological investigation, we have found out that the type of B lymphocyte was absent. Level of IgG was 10 times less; $\operatorname{IgA}$, IgM and IgE levels were 3 to 8 times less than the norm. There were some noticeable changes in the peripheral blood indexes: leukocytosis, lymphopenia and monocytosis; quantity of Tlymphocytes: absolute number of CD4+ lymphocytes increased, CD3+ and CD8+ lymphocytes were also high. Phagocyte activity in NBT, absolute number of NK cells and IRI index were 2 times lower than the norm. Some these findings are depicted on Table 2.

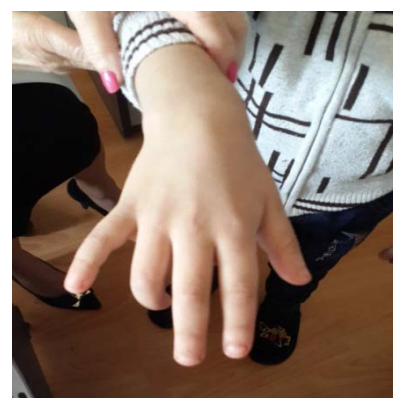

Figure 3. Clinical fetures of Rheumatoid Arthritis in patient with AGM4.

Table 2. Periodically immunological results of AGM4 patient.

\begin{tabular}{cccc}
\hline & Before İVİG & After IVIG & Norm \\
\hline Leukocyte $10^{9} / 1$ & 20.6 & 14.2 & $4.0-7.3$ \\
Lymphocyte $\%$ & 26 & 29 & $36-43$ \\
İgA (q/l) & 0 & 0.1 & $0.83-2.17$ \\
İgM (q/l) & 0 & 0.3 & $0.55-2.10$ \\
İgG (q/l) total & 0.6 & 5.0 & $6.5-14.1$ \\
IgE (ME/ml) & 0 & 0.8 & $0-60$ \\
\hline
\end{tabular}




\subsection{Molecular Genetics}

\section{HOMOZYGOUS VARIANTS}

BLNK: OMIM AR for Agammaglobulinemia 4 (absent pre-B, mature B cells, but normal numbers of pro- $B$ cells; recurrent otitis, pneumonia). $B L N K$ is essential for normal B-cell development.

HETEROZYGOUS VARIANTS (only inherited AD or possible compound heterozygous)

CFI: CFI deficiency can cause hemolytic uremic syndrome with clinical impact, such as hemolytic anemia, proteinuria, decreased renal function and hypertension.

PSTPIP1: OMIM AD: Pyogenic sterile arthritis, pyoderma gangrenosum, and acne syndrome.

C5: OMIM AD and AR for complement component 5 deficiency (seborrheic dermatitis, intractable diarrhea, recurrent local and systemic infections) (Table 3).

Genetically analysis has discovered the presence of abnormal homozygous BLNK, heterozygous CFI, PSTPIP1 and C5 genes.

\subsection{Treatment}

Antibacterial treatment during 2 weeks, non-steroid and steroid medicines, other symptomatic treatment. Replacement therapy by IVIG-Octagam was given in dose $400-600 \mathrm{mg} / \mathrm{kg}$, every 4 weeks, but it was not regularly received.

Table 3. Genetic results of our patient M. D., 7 years old.

\begin{tabular}{|c|c|c|c|c|c|c|c|c|c|}
\hline HOM & & & & & & & & & \\
\hline GENE & CHR & POS & SNP ID & IMPACT & $\mathrm{AA}$ & ID & MAF & READS & CADD score \\
\hline$B L N K$ & 10 & 97964346 & rs184808145 & STOP_GAINED & $\mathrm{R} 282^{*}$ & ENST00000224337 & $<0.01$ & 684 & 38 \\
\hline \multicolumn{10}{|l|}{ HET } \\
\hline GENE & CHR & POS & SNP ID & IMPACT & AA & ID & MAF & READS & CADD score \\
\hline$I L 12 B$ & 5 & 158749490 & rs139186048 & MISSENSE & E132K & ENST00000231228 & $<0.01$ & 426 & 26.3 \\
\hline DOCK 8 & 9 & 418066 & . & SPLICE_SITE_ACCEPTOR & NA & ENST00000453981 & NA & 155 & 18.77 \\
\hline$C F I$ & 4 & 110682814 & . & MISSENSE & D173N & ENST00000394635 & $<0.01$ & 645 & 0.001 \\
\hline$P S T P I P 1$ & 15 & 77310863 & rs201872851 & MISSENSE & T68M & ENST00000558012 & $<0.01$ & 450 & 25 \\
\hline$V P S 13 B$ & 8 & 100844858 & rs149842139 & MISSENSE & $\begin{array}{c}\text { R3223 } \\
\text { W }\end{array}$ & ENST00000358544 & $<0.01$ & 559 & 25.4 \\
\hline$N C F 4$ & 22 & 37267701 & rs150103256 & MISSENSE & V160M & ENST00000397147 & $<0.01$ & 204 & 4.579 \\
\hline$D N A A F 1$ & 16 & 84208329 & rs139519641 & SPLICE_SITE_DONOR & NA & ENST00000378553 & $<0.01$ & 528 & 11.68 \\
\hline$C 5$ & 9 & 123785738 & rs34552775 & MISSENSE & L354M & ENST00000223642 & $<0.01$ & 404 & 25 \\
\hline$N C F 1$ & 7 & 74197326 & . & MISSENSE & N166D & ENST00000289473 & $<0.01$ & 673 & 0.003 \\
\hline
\end{tabular}

GENE: gene name; MPACT: consequence of variant (e.g. missense, stop gain, splice-site); CHR: chromosome; POS: chromosomal position (bases); ID: Transcript ID; SNP ID: rs number; R: base in reference genome; MAF: minor allele frequency; A: alternative base in sample; NA: not annotated; AA: change on amino acid level; READS: number of sequencing reads covering the variant. 


\section{Outcomes}

The patient is under our control for 2 years. In this period the number of diseases, especially pneumonia, decreased against the background of immunological treatment. Pain in the joints falls and can open the finger. The patient's parents were informed of the illness, and a prenatal diagnosis was recommended during the next pregnancy.

\section{Conclusion}

Thus, based on the detection of a serious deficiency of humoral immunity and BLNK gene mutation, patient has rarely diagnosed disease-agammaglo-bulinemia type 4 (AGM4).

\section{References}

[1] Schwartz, R.A. (2017) Bruton Agammaglobulinemia. http://emedicine.medscape.com/article/884942-overview

[2] Kniffin, C.L. (2010) Agammaglobulinemia 4, Autosomal Recessive. http://www.omim.org/entry/613502

[3] Pituch-Noworolska, A., Mach-Tomalska, H., Szaflarska, A. and Adamek, D. (2016) Shulman Disease (Eosinophilic Fasciitis) in X-Linked Agammaglobulinemia. Polish Journal of Pathology, 67, 183-188. https://doi.org/10.5114/pjp.2016.61456

[4] Abolhassani, H., Vitali, M. and Lougaris, V. (2016) Cohort of Iranian Patients with Con-genital Agammaglobulinemia: Mutation Analysis and Novel Gene Defects. Expert Review of Clinical Immunology, 12, 479-486. https://doi.org/10.1586/1744666X.2016.1139451

[5] Ferrari, S., Zuntini, R., Lougaris, V., et al. (2007) Molecular Analysis of the Pre-BCR Complex in a Large Cohort of Patients Affected Byautosomal-Recessive Agammaglobulinemia. Genes and Immunity, 8, 325-333. https://doi.org/10.1038/sj.gene.6364391

[6] Vickery, J., Michael, C. and Lew, D. (2013) Evaluation of B Lymphocyte Deficiencies. Cardiovascular \& Hematological Disorders-Drug, 13, 133-143. https://doi.org/10.2174/1871529X11313020006

[7] Chin, T.W. (2014) Agammaglobulinemi. http://emedicine.medscape.com/article/884942-overview

[8] Conley, M.E. (2013) Autosomal Agammaglobulinemia. http://www.orpha.net/consor/cgi-bin/OC_Exp.php?lng=EN\&Expert=33110

[9] Yuvaraj, S. and Hendriks, R.W. (2012) Blnk (B-Cell-Linker). http://atlasgeneticsoncology.org/Genes/GC_BLNK.html

[10] Agarwal, S. and Mayer, L. (2009) Pathogenesis and Treatment of Gastrointestinal Disease in Antibody Deficiency Syndromes. Journal of Allergy and Clinical Immunology, 124, 658. https://doi.org/10.1016/j.jaci.2009.06.018

[11] Slotta, J.E., Heine, S., Kauffels, A., et al. (2011) Gastrectomy with Isoperistaltic Jejunal Parallel Pouch in a 15-Year-Old Adolescent Boy with Gastric Adenocarcinoma and Autosomal Recessive Agammaglobulinemia. Journal of Pediatric Surgery, 46, e21-24. https://doi.org/10.1016/j.jpedsurg.2011.06.005

[12] Vancikova, Z., Freiberger, T., Vach, W., Trojanek, M., Rizzi, M. and Janda, A. 
(2013) X-Linked Agammaglobulinemia in Community-Acquired Pneumonia Cases Revealed by Immunoglobulin Level Screening at Hospital Admission. Clin Padiatr, 225, 339-342. https://doi.org/10.1055/s-0033-1354415

Submit or recommend next manuscript to OALib Journal and we will provide best service for you:

- Publication frequency: Monthly

- 9 subject areas of science, technology and medicine

- Fair and rigorous peer-review system

- Fast publication process

- Article promotion in various social networking sites (LinkedIn, Facebook, Twitter, etc.)

- Maximum dissemination of your research work

Submit Your Paper Online: Click Here to Submit

Or Contact service@oalib.com 